\title{
Rancang Bangun Home Automation Berbasis Ethernet Shield Arduino
}

\author{
Dewi Lestari ${ }^{1, \uparrow}$, Muhammad rizki daimunte ${ }^{2}$ \\ ${ }^{1}$ Program Studi Sistem Informasi, Fakultas Industri Kreatif dan Telematika, Universitas Trilogi \\ Jl. TMP Kalibata No.1, Jakarta, Indonesia \\ ${ }^{2}$ Program Studi Fisika, Fakultas Sains dan Teknologi, Universitas Islam Negeri Syarif Hidayatullah \\ Jakarta, Jalan Ir. H. Djuanda No.95, Ciputat, Kota Tangerang Selatan, Banten, 15412, Indonesia \\ †dewy24@trilogi.ac.id
}

\begin{abstract}
Abstrak
Home Automation system adalah sistem otomatisasi rumah yang dapat membuat rumah menjadi lebih hemat dengan penggunaan energi listrik yaitu dengan cara meng-on/off-kan berbagai peralatan seperti lampu , ac, kipas angin, tv, pompa air, motor pagar, motor garasi, motor gorden dan lain-lain. Home automation pada penelitian ini menggunakan Ethernet shield Arduino, empat buah lampu, dan sensor DHT22 untuk mengkontrol temperatur dan kelembaban. Home Automation yang telah dibuat dapat bekerja baik dan lancar dengan kecepatan respon waktu rata-rata 2 detik antara saat penekanan tombol saklar ON/OFF pada tampilan broswer dengan rangkaian home automation. Dan hasil pengujian pada sensor DHT22 memiliki ketelitian sebesar $98.65 \%$ untuk pengukuran temperatur dan ketelitian sebesar $98.72 \%$ untuk pembacaan kelembaban.
\end{abstract}

Kata Kunci: Arduino Uno, Ethernet Shield Arduino, Lampu, Sensor DHT22

\begin{abstract}
The home Automation system is a home automation system that makes your home more efcient than the use of electrical energy, giving you the ease to turn on / off various equipment such as electric lights, air conditioners, fans, TVs, water pumps, fencing motors, garage motors, Motor Curtains, etc. Home automation in this study uses an Arduino Ethernet shield, four lamps, and a DHT22 sensor to control temperature and humidity. The home automation test results have a response time of 2 seconds between pressing the ON / OFF switch on the browser display and the home automation device circuit. And the test results on the DHT 22 sensor have an accuracy of $98.65 \%$ for the measurement of air temperature and accuracy of $98.72 \%$ for the reading of air humidity
\end{abstract}

Keywords: Arduino Uno, Ethernet Shield Arduino , Lamp, Sensor DHT22

DOI : 10.15408/fiziya.vi1.15249 


\section{PENDAHULUAN}

Home Automation dapat diibaratkan sebagai ekstensi perumahan dari "otomatis bangunan". Hal ini berhubungan dengan kegiatan dan pekerjaan di rumah yang otomatis terlaksana. Home Automation juga termasuk kegiatan sistem kontrol yang terpusat pada pencahayaan, air conditioning (heat, ventilasi dan air conditioning), peralatan, dan framework lainnya, untuk memberikan kenyamanan, keamanan, efisiensi energi dan kemudahan yang lebih baik. Dimana sebuah sistem otomatisasi rumah ini dapat mengintegrasikan perangkat listrik di rumah dengan satu sama lainnya. Teknik yang digunakan dalam home automation termasuk yang diotomatisasi bangunan dengan pengendalian kegiatan domestik seperti sistem hiburan rumah, house plant dan penyiraman halaman dan lainya. Perangkat ini dapat dihubungkan dengan jaringan komputer untuk memungkinkan kontrol dengan komputer pribadi dan memungkinkan akses remote dari internet. Dengan integrasi teknologi informasi dan lingkungan rumah, sistem dan peralatan dapat berkomunikasi secara terpadu yang menghasilkan kenyamanan, efisiensi energi dan manfaat keselamatan[1].

Ethernet Shield ini menambah kemampuan Arduino board untuk menghubungkan ke system jaringan komputer. Ethernet shield ini berbasiskan cip ethernet Wiznet W5100. Ethernet library yang digunakan dalam menulis program agar Arduino board dapat terhubung ke jaringan dengan menggunakan Arduino ethernet shield [2]. HTML merupakan salah satu format yang digunakan dalam pembuatan dokumen (web page) dan aplikasi yang berjalan di halaman web. Dokumen HTML ini merupakan dokumen yang disajikan dalam web browser dimana web browser ini merupakan suatu program software aplikasi atau perangkat yang dapat digunakan untuk mencari informasi dalam jaringan internet dari sebuah media seperti situs, blog, jejaring sosial, dan lain sebagainya yang tersimpan di dalam internet [3][4]. Penelitian ini adalah pengembangan dari penelitian yang berjudul "Pemantauan isi kulkas menggunakan ethernet shield R3 berbasis Arduino uno". Dimana penelitian tersebut bertujuan hanya untuk memantau seluruh isi didalam kulkas[5].

Pada penelitian ini dikembangkan menjadi home automation yang mengendalikan alat-alat elektronik dengan web browser. Rancang bangun ini menggunakan Arduini Uni sebagai prosessor atau pengendali beserta modul ethernet shield berupa web browser untuk monitoring kondisi lampu serta sensor DHT22 sebagai input data temperatur dan kelembaban. Rancang bangun home automation ini akan ditampilkan dengan tampilan web, dimana arduino ethernet shield sebagai server sedangkan PC sebagai client. Dalam aplikasi ini peneliti membatasi home automation dengan empat buat saklar atau relay untuk memutus sumber listrik dari PLN untuk peralatan rumahan, dimana empat buah saklar ini bisa dibagi untuk lampu, pompa air, kipas, kulkas dan sebagainya tergantung kebutuhan dan keinginan pembuat. Sedangkan sensor DHT22 digunakan sebagai input data untuk temperatur dan kelembaban yang akan ditampilkan via web browser. Relay disini digunakan sebagai output untuk mengatur saklar dengan kontrol via web browser yang akan menampilkan status perangkat dalam kondisi hidup atau mati melalui refresh page otomatis dengan bahasa logika HTML.

Didalam aplikasi home automation kontrol yang berbasis bahasa logika web HTML ini terdapat CSS yang digunakan untuk memperindah tampilan serta terdapat data dari sensor DHT22 berupa temperatur dan kelembaban ruangan. Terdapat empat buat opsi kontrol relay masingmasing beserta kondisinya apakah hidup atau mati sehinggga kita mudah menyalakan relay atau saklar hanya dengan menekan klik hidup atau matikan, maka keadan saklar tersebut akan berubah.

\section{METODE}

Penelitian ini dilakukan dari bulan Juli sampai Desember 2019. Perancangannya dibuat di Pusat Laboratorium Terpadu UIN Syarif Hidayatullah Jakarta. Di bawah ini adalah rangkaian dari home automation yang telah dibuat. 


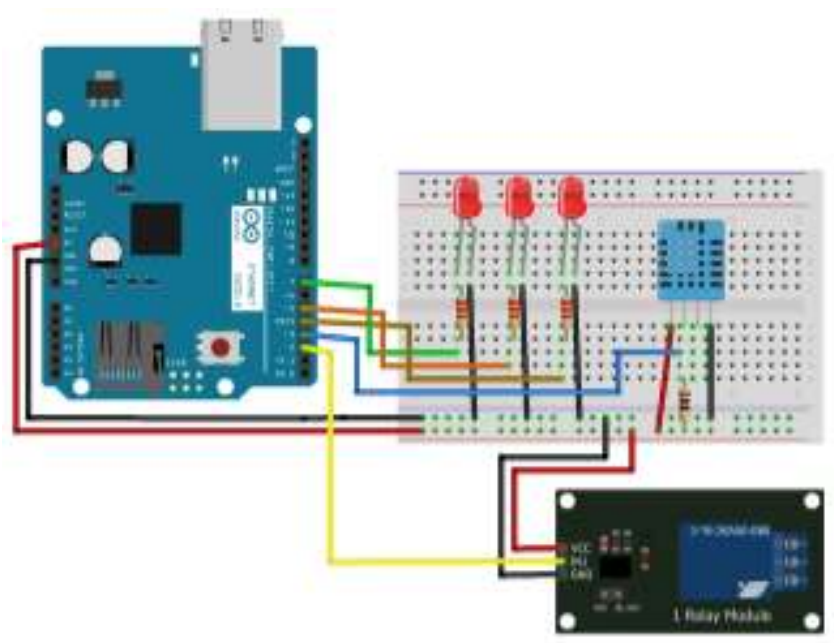

Gambar 1. Skematik Home Automation

Pada gambar di atas dapat dijelaskan bahan dan alat yang digunakan dalam penelitian yaitu

1. Arduino uno digunakan sebagai masukan dan keluaran data. Jenis Pin yang dipakai dalam Arduino terdiri dari:
a. Pin 7, Pin 5 dan pin 4 digunakan untuk output lampu
b. Pin3 digunakan sensor DHT22 sebagai input untuk mengetahui temperatur dan kelembaban di ruangan.
c. Power, Ground dan Vcc sebagai sumber tegangan

2. Shield Ethernet Arduino yang letaknya digabungkan dengan Arduino uno sebagai sumber internet IP address

3. Sensor DHT22 untuk pengatur temperatur dan kelembaban ruangan

4. Relay digunakan untuk penghubung dengan lampu dari Arduino uno

5. Kabel UTP atau kabel telepon sebagai penghubung shield ethernet Arduino dengan laptop

6. Lampu sebagai output yang dikendalikan

7. Resistor sebagai penghambat tegangan yang masuk ke LED agar tidak kelebihan arus

\section{Cara Konfigurasi Sistem kontrol suhu dan Arduino Ethernet shield}

1. Langkah awal melakukan bridge adapter pada pc/ laptop kita.

2. Mensetting IP Address pada Ethernet menjadi

IP Address 192.168.1.10

Netmask : 255.255.255.0

Gateway : 192.168.1.1

Saat waktu habis maka buzzer akan berbunyi serta led akan menyala.

3. Langkah selanjutnya membuka aplikasi Arduino IDE dan pada tab Tools pilih board prosesor serta sesuaikan dengan port Arduino yang digunakan

4. Langkah terakhir masukan kode di bawah dan upload ke Arduino

\section{Cara Testing Sistem kontrol suhu dengan Arduino Ethernet shield}

1. Gabungkan Arduino uno dan Ethernet Shield, kemudian sambungkan dengan laptop menggunakan kabel LAN

2. Masuk pada program CMD di laptop selanjutnya ping IP Ethernet yang digunakan pada penelitian ini

3. Masuk pada CMD kemudian lakukan ping pada IP ethernet pada penelitian ini, peneliti menggunakan IP Address 192.168.1.177. jika hasil ping reaply maka Ethernet sudah dapat dipakai dan terhubung dengan laptop

4. Buka Broswer selanjutnya pada kolom URL masukan IP Address 192.168.1.177 


\section{HASIL DAN PEMBAHASAN}

Home automation ini memiliki tampilan input berupa temperatur, kelembapan dan empat buat saklar yang diatur HIDUP atau MATI serta kondisi status perangkat, berikut data yang akan ditampilkan dengan web browser dengan PC sebagai client dan Arduino ethernet shield sebagai server.

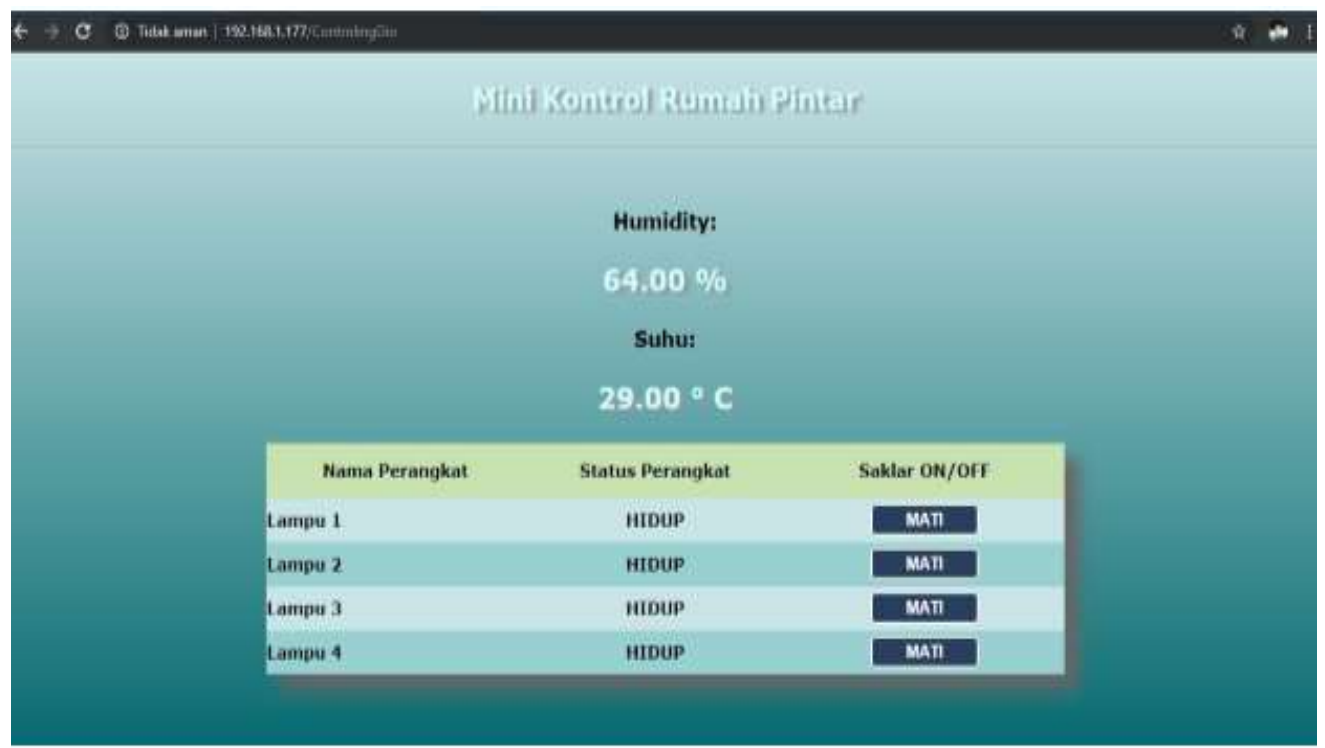

Gambar 2. Tampilan browser menggunakan shield ethernet Arduino

Pada gambar 2 di atas terdapat IP Address : 192.168.1.10 yang digunakan untuk menampilkan sistem home automation yang telah dibuat. Pada home automation yang terlihat adalah besarnya temperatur dan kelembaban ruangan serta empat lampu ruangan yang akan kita kendalikan baik dalam keadaan hidup atau mati. Saklar on/off di atas dapat ditekan untuk mengendalikan lampu 1-4 dan nantinya akan terlihat status lampu saat itu hidup/mati. Hasil Pengujian home automation dilakukan dengan empat metode untuk mengetahui keakuratan kecepatan waktu tampilan di web dan rangkaian sebagai berikut

\section{Hanya satu saklar atau relay pada posisi hidup}

Pengujian ini dilakukan dengan menekan pada tampilan saklar on untuk lampu 1 dan dapat diketahui status perangkat serta rangkaian lampunya
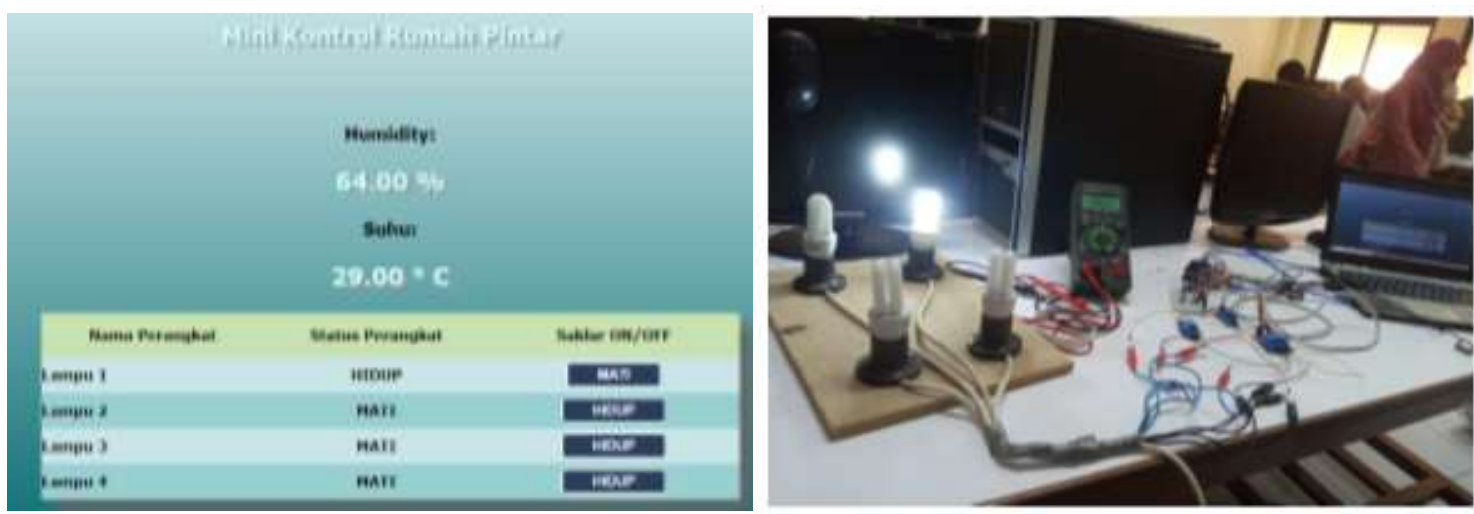

Gambar 3. Hasil Tampilan browser dan Lampu kondisi satu saklar kondisi hidup 
Gambar 3 menunjukan bahwa ketika posisi saklar mati maka kondisi lampu 1 hidup dan terlihat pula pada broswer bahwa status perangkat hidup sehingga disebelah kanan terlihat lampu 1 menyala.

\section{Dua saklar atau relay pada posisi hidup}

Hasil pengujian dua saklar pada posisi hidup dilakukan dengan menekan tampilan saklar on pada Lampu 1 dan Lampu 2 dan dapat diketahui status perangkat serta rangkaian lampunya
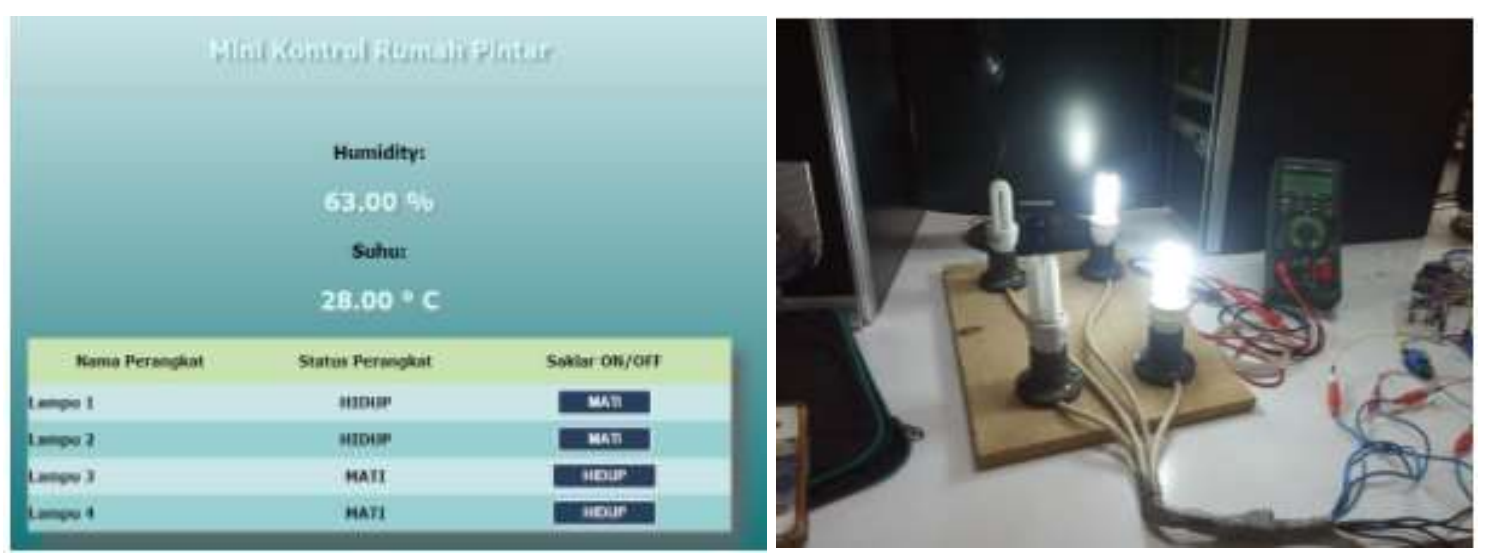

Gambar 4. Tampilan browser dan rangkaian kondisi dua saklar kondisi hidup

Dari gambar 4 terlihat bahwa posisi saklar mati untuk lampu 1 dan lampu 2 maka pada status perangkat akan muncut status hidup sehingga pada rangkaian lampu 1 dan lampu 2 akan menyala

\section{Tiga saklar atau relay pada posisi hidup}

Hasil pengujian tiga saklar atau relay pada posisi hidup, lampu 2, dan lampu 3 maka akan terjadi perubahan di bagian status perangkat serta rangkaian lampunya .
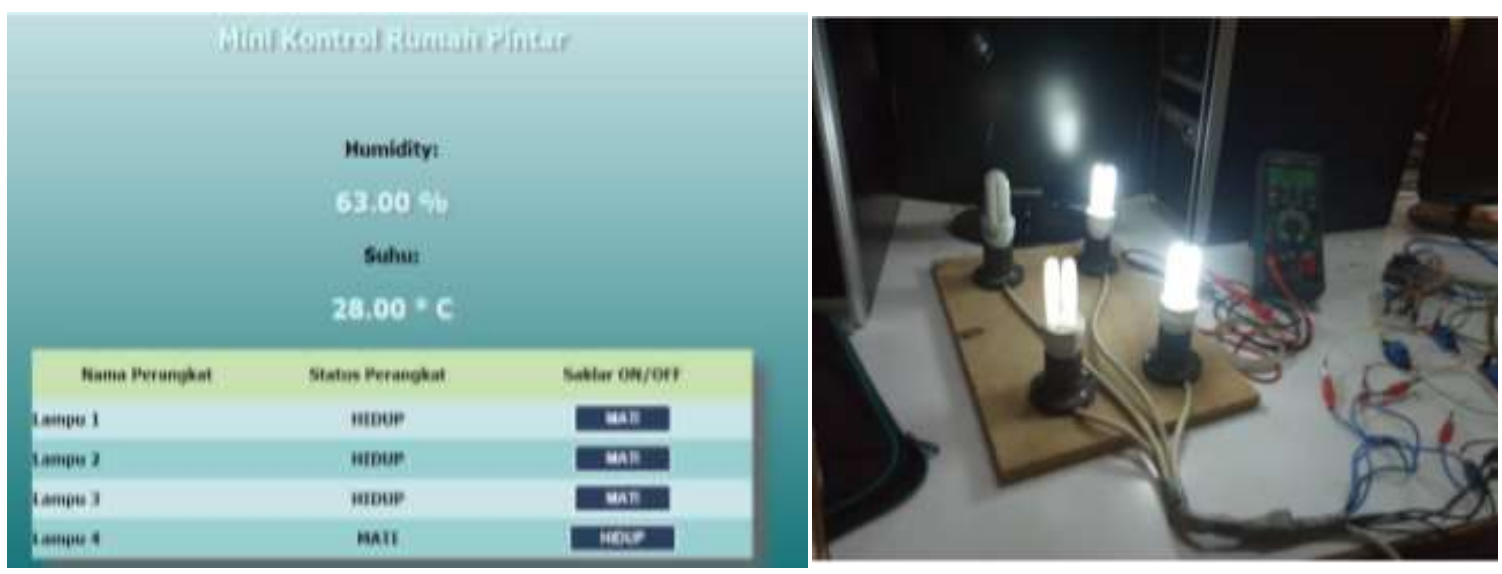

Gambar 5. Tampilan browser dan rangkaian kondisi tiga saklar kondisi hidup

Dari gambar 5 terlihat bahwa posisi saklar mati untuk lampu 1 dan lampu 2, dan lampu 3 maka pada status perangkat yang sebelumnya mati akan berubah menjadi hidup sehingga pada rangkaian lampu 1, lampu 2, dan lampu 3 akan menyala. 


\section{Empat saklar atau relay pada posisi hidup}

Hasil pengujian ini dilakukan dengan cara menekan pada tampilan saklar mati pada lampu 1, lampu 2, lampu 3, dan lampu 4 maka akan terjadi perubahan di bagian status perangkat serta rangkaian lampunya
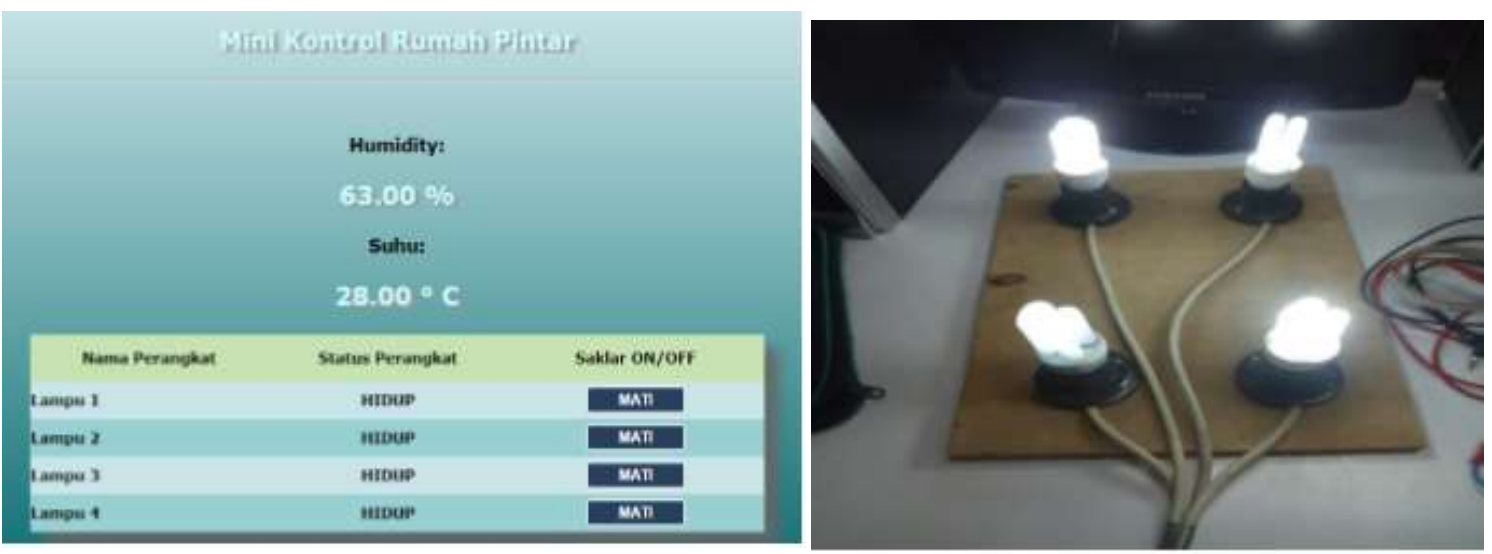

Gambar 6. Tampilan Browser dan Rangkaian kondisi empet saklar kondisi hidup

Dari gambar 6 terlihat bahwa posisi saklar mati untuk lampu 1, lampu 2, lampu 3, dan lampu 4 maka pada status perangkat yang sebelumnya mati akan berubah menjadi hidup sehingga pada rangkaian lampu 1, lampu 2, lampu 3 dan lampu 4 akan menyala.

Dari pengujian empat metode yang digunakan dapat diketahui hasil kecepatan waktunya sebagai berikut. tabel di bawah ini menunjukkan hasil kecepatan waktu respon penekanan tombol saklar on/off pada tampilan browser dan respon lampu hidup/mati pada rangkaian diperlihatkan sebagai berikut

Tabel 1. Hasil kecepatan respon antara penekanan tombol saklar on/off di browser web dan kondisi lampu pada rangkaian

\begin{tabular}{cccc}
\hline No & $\begin{array}{c}\text { Waktu } \\
\text { Penekanan Tombol } \\
\text { Saklar ON/OFF }\end{array}$ & $\begin{array}{c}\text { Waktu } \\
\text { Kondisi Lampu } \\
\text { dirangkaian }\end{array}$ & $\begin{array}{c}\text { Selisih Waktu } \\
\text { (detik) }\end{array}$ \\
\hline 1 & $09: 11: 35$ & $09: 11: 37$ & 2 detik \\
2 & $09: 12: 37$ & $09: 12: 39$ & 2 detik \\
3 & $09: 13: 39$ & $09: 13: 41$ & 2 detik \\
4 & $09: 14: 41$ & $09: 14: 43$ & 2 detik \\
5 & $09: 15: 43$ & $09: 15: 45$ & 2 detik \\
6 & $09: 16: 45$ & $09: 16: 47$ & 2 detik \\
7 & $09: 17: 47$ & $09: 17: 49$ & 2 detik \\
8 & $09: 18: 49$ & $09: 18: 51$ & 2 detik \\
9 & $09: 11: 35$ & $09: 11: 37$ & 2 detik \\
\hline 10 & \multicolumn{3}{c}{ Rata-rata } \\
\hline \multicolumn{3}{c}{}
\end{tabular}

Pada tabel 1 dapat dijelaskan dari 10 pengujian alat bahwa selisih waktu antara penekanan tombol saklar on/off hanya mengalami keterlambatan waktu rata-rata sebesar 2 detik dari waktu kondisi lampu dirangkaian.

\section{Hasil Pengujian sensor DHT22}

Pengujian sensor DHT22 ini dilakukan untuk mengetahui ketelitian pembacaan dari sensor DHT22. Pengujian dilakukan dengan cara membandingkan hasil pembacaan sensor DHT22 
dengan Termo Hygrometer HTC-2 Y1599. Adapun hasil dari pengujian yang telah dilakukan dapat dilihat pada tabel 2 dibawah ini:

Tabel 2. Hasil Pengujian Sensor DHT22

\begin{tabular}{ccccc}
\hline \multirow{2}{*}{ No } & \multicolumn{2}{c}{$\mathrm{DHT} 22$} & \multicolumn{2}{c}{$\mathrm{HTC}$} \\
& $\mathrm{T}\left({ }^{\circ} \mathrm{C}\right)$ & $\mathrm{H}(\%)$ & $\mathrm{T}\left({ }^{\circ} \mathrm{C}\right)$ & $\mathrm{H}(\%)$ \\
\hline 1 & 27.7 & 56.3 & 27.8 & 58 \\
2 & 27.5 & 56.5 & 27.9 & 58 \\
3 & 27.3 & 56.7 & 27.8 & 58 \\
4 & 27.2 & 56.8 & 27.6 & 58 \\
5 & 27.2 & 56.6 & 27.4 & 57 \\
6 & 27 & 56.6 & 27.4 & 57 \\
7 & 27 & 56.6 & 27.4 & 57 \\
8 & 26.8 & 56.6 & 27.4 & 57 \\
9 & 26.8 & 56.9 & 27.2 & 57 \\
10 & 26.9 & 57 & 27.2 & 57 \\
\hline Rata-rata & 27.14 & 56.66 & 27.51 & 57.4 \\
\hline
\end{tabular}

Dari table 2 hasil pengujian sensor DHT22 di atas dapat di tentukan besar nilai rata-rata temperatur 27.14 sehingga dapat diketahui ketelitian sebesar $98.65 \%$ dan nilai rata-rata kelembaban 56.66 sehingga besar ketelitian kelembaban 98.72\%. Dalam menentukan ketelitian/ keakuratan sensor dilakukan melalui tahap menentukan nilai standar deviasi, nilai ralat mutlak, nilai ralat nisbi dan terakhir didapatkan nilai ketelitian[5].

\section{PENUTUP}

Berdasarkan hasil rancang bangun home automation dengan shield Ethernet Arduino maka dapat ditarik kesimpulan sebagai berikut:

1. Telah berhasil merancang dan membangun home automation menggunakan shield ethernet Arduino dengan IP Address 192.168.1.10 dan bekerja dengan baik

2. Kecepatan waktu respon home automation ini saat penekanan tombol saklar ON/OFF hanya mengalami keterlambatan waktu rata-rata sebesar 2 detik dengan waktu kondisi lampu dirangkaian.

3. Hasil pengujian pada sensor DHT 22 memiliki nilai ketelitian sebesar $98.65 \%$ untuk pengukuran temperatur udara dan ketelitian sebesar $98.72 \%$ untuk pembacaan kelembaban udara..

\section{REFERENSI}

[1] Pengertian home automation : donnysetiaji.blogspot.com/2014/12/pengertian-home-automationsystem.html

[2] Anonymous. 2013. "Master Mikro Arduino". 2013. E-book dari situs http://inkubatorteknologi.com/avrsiap-guna/paket-lengkap-belajararduino

[3] Safaat, Nazruddin. 2011. "Android, Pemrograman Aplikasi Mobile Smartphone dan Tablet PC Berbasis Android". Penerbit INFORMATIKA: Bandung

[4] Oberon Micro Systems. 2013. "Access Devices From The Web". Dalam situs http://www.yaler.net/.

[5] Haris, Ahmad." Pemantauan isi kulkas menggunakan ethernet shield R3 berbasis Arduino uno ". Program Studi Teknik Elektronika Jurusan Pendidikan Teknik Elektronika Fakultas Teknik Universitas Negeri Yogyakarta.2016

[6] Lestari, Dewi, and Yaddarabullah Yaddarabullah. "Perancangan Alat Pembacaan Meter Air PDAM Menggunakan Arduino Uno." Al-Fiziya: Journal of Materials Science, Geophysics, Instrumentation and Theoretical Physics 1.2 (2018): 36-41.

[7] M. Pamungkas, Hafiddudin, dan Y. S. Rohmah, "Perancangan dan Realisasi Alat Pengukur Intensitas Cahaya,” J. ELKOMIKA, vol. 3, no. 2, hlm. 120-132, 2015. 
[8] R. Rinaldy, R. F. Christianti, dan D. Supriyadi, "Pengendalian Motor Servo Yang Terintegrasi Dengan Webcam Berbasis Internet Dan Arduino," J. Inform. Dan Elektron., vol. 5, no. 2, Apr 2014, doi: 10.20895/infotel.v5i2.59.

[9] Ichwan, Muhammad, Milda Gustiana Husada, and M. Iqbal Ar Rasyid. "Pembangunan

Prototipe Sistem Pengendalian Peralatan Listrik Pada Platform Android." Jurnal Informatika (2013): 13-25.

[10] Humphries, L. Scott, et al. "Home automation system." U.S. Patent No. 5,621,662. 15 Apr. 1997. 